\title{
DOM E CONFLITO: SANTIDADE E DEPENDÊNCIA PESSOAL NO REINO VISIGODO DE TOLEDO ${ }^{1}$ \\ GIFT AND CONFLICT: HOLINESS AND PERSONAL DEPENDENCE IN THE VISIGOTHIC KINGDOM OF TOLEDO
}

Paulo Pachá ${ }^{2}$

\begin{abstract}
Resumo: O artigo examina o emprego do conceito de dom (ou troca de presentes) pela medievalística contemporânea para enfatizar a ausência do seu emprego na análise de relações marcadas pelo conflito. Por meio da análise de três hagiografias produzidas na Península Ibérica durante o século VII, argumenta-se que o conceito de dom é um instrumento teórico importante para desvelar a produção e reprodução de relações desiguais. Durante o período em questão, essas relações estiveram na base de um processo amplo de expansão da dominação aristocrática sobre o campesinato através da generalização das relações de dependência pessoal.
\end{abstract}

Palavras-chave: visigodos; dom; hagiografia; dependência pessoal.

Abstract: This article explore how the concept of gift-exchange was employed by the historiography of the Middle Ages to highlight its absence in the analyses of relationships marked by conflict. Through the analysis of three hagiographies produced in the Iberian Peninsula during the seventh century, it is argued that the concept of gift-exchange is an important theoretical tool to unveil the production and reproduction of unequal relationships. During this period, those relationships were the basis of a wide expansion process of aristocratic domination over the peasantry through the generalization of the relations of personal dependence.

Keywords: Visigoths; gift; hagiography; personal dependence.

\section{Dom e Aristocracia}

O conceito de dom foi acolhido como um filho perdido pelos medievalistas nas últimas décadas e é hoje extremamente popular. Desde a publicação do ensaio clássico de Marcel Mauss em 1924, o conceito foi desenvolvido e apropriado de maneiras muito diversas (MAUSS, 2003). Nas mãos dos medievalistas o conceito de Mauss sofreu transformações inspiradoras e inovadoras, desafiando velhos modelos, pressuposições e soprando vida nova no conceito de troca de presentes. Hoje a troca de presentes é compreendida como um ato plural, uma relação plástica e, acima de tudo, uma negociação.

\footnotetext{
${ }^{1} \mathrm{O}$ presente artigo é uma versão traduzida e substancialmente alterada do artigo publicado previamente (em inglês) na revista Networks and Neighbours (v. 2, n. 2, p. 288-324, 2014). O texto foi substancialmente modificado com base em críticas e comentários após a apresentação no Ciclo de Debates do NIEP-Marx-PréK (2015), razão pela qual o autor gostaria de agradecer aos colegas presentes à discussão.

${ }^{2}$ Doutor em História pela Universidade Federal Fluminense (2015). Estágio de Pós-Doutorado pelo Institut für Mittelalterforschung, Áustria (2016). Professor de História Medieval na Escola Superior de Ciências Sociais e História da Fundação Getúlio Vargas. E-mail: phpacha@gmail.com.
} 
Em uma síntese recente e extremamente ampla de como os medievalistas usaram o(s) conceito(s) de troca de presente, A. Bijsterveld pretendeu "esboçar o atual status quaestionis da análise do dom medieval" e destacou como "desde a década de 1980 medievalistas nos Estados Unidos e Europa têm aplicado [...] o conceito de troca de presentes ao estudo dos dons feito por aristocratas para comunidades religiosas" (BIJSTERVELD, 2001, p. 123). De acordo com a análise de Bijsterveld, a ideia de reciprocidade aparecia como o fundamento da troca de presentes. Segundo o autor, "é possível observar uma estratégia social geral de troca de presentes ao longo da Idade Média, através da qual membros da aristocracia estabeleceram relações duradouras com instituições religiosas" (BIJSTERVELD, 2001, p. 124). Dessa forma, a análise de Bijsterveld expressa também uma correlação direta entre o atual status quaestionis do campo e a troca de presentes entre aristocratas e comunidades religiosas. Trata-se, portanto, de "estratégia social geral" envolveria apenas a aristocracia (laica e eclesiástica).

Empreendendo uma análise semelhante a de Bijsterveld, ainda que cronologicamente mais restrita, Florin Curta (2006) examinou uma série de trocas de presentes entre aristocratas merovíngios e carolíngios. Seu principal objetivo era negar que a reciprocidade seria o fundamento da troca de presentes. Segundo Curta (2006, p. 682), “o valor desigual dos bens trocados (uma relíquia de valor inestimável por prata e comida, por exemplo) excluiria qualquer conceito de reciprocidade". Recorrendo à noção de potlatch desenvolvida por Mauss, Curta argumentou que os dons trocados entre aristocratas seriam "expressões de um desejo de por o recipiente duradouramente em débito, para prevalecer e, portanto, dominar" (2006, p. 698). Segundo Curta, a troca de presentes não seria sobre reciprocidade, mas dominação.

A análise de Curta aponta, portanto, para uma progressiva restrição do conceito de troca de presentes. Segundo o autor, a troca de presentes era "uma forma de guerra alternativa na qual aristocratas assertivos se engajavam quando competiam uns com os outros por poder". A partir dessa definição, Curta restringe ainda mais a abrangência social da relação ao afirmar que "dons circulavam em um círculo restrito de indivíduos nas sociedades merovíngias e carolíngias", ou que "troca de presentes não era parte de uma rede geral de produção e distribuição". Logicamente, ambas as afirmativas decorrem do fato de que o pressuposto geral do artigo é uma análise da troca de presentes intra-aristocrática (2006, p. 698). Dessa forma, o que nós realmente encontramos aqui é uma fusão das noções de sociedade e aristocracia: como se as sociedades merovíngia e carolíngia fosse sociedades compostas somente por aristocratas. 
As duas recentes interpretações do conceito discutidas acima enfatizam questões importantes e podem funcionar como uma plataforma a partir do qual um novo entendimento da troca de presentes pode ser desenvolvido. Por um lado, não é possível definir o fundamento unilateral da troca de presentes (medieval) como reciprocidade (mesmo idealmente) apenas pela identificação completa de dons como ofertas religiosas (donatio pro anima) (BIJSTERVELD, 2001, p. 128); por outro lado, não é possível deslocar completamente a reciprocidade de sua função de fundamento da troca de presentes e substituíla pela dominação (intencional ou acidental) apenas baseado no valor desigual de um dom e seu contra-dom (CURTA, 2006, p. 682). Dessa forma, os resultados contraditórios das análises de Bijsterveld e Curta permitem duas conclusões: 1) existe uma relação complexa entre reciprocidade e dominação na troca de presentes; 2) tal relação só pode ser analisada a partir de um entendimento mais amplo da sociedade, i.e., para além das aristocracias (laicas ou eclesiásticas).

Como os dois artigos citados deixam claro, a maior parte das discussões conceituais sobre a troca de presentes medieval tem uma tendência a partilhar um enquadramento teórico geral para toda a Idade Média Ocidental ou, pelo menos, entre os dois grandes blocos cronológicos da Alta e Baixa Idade Média (ALGAZI et al., 2003; DAVIES; FOURACRE, 2010). Dessa forma, é possível desvelar algumas linhas de força dos estudos da troca de presentes medieval. Em resumo, boa parte das análises compartilha pressupostos teóricos gerais que podem der definidos como uma circunscrição dupla (e dialética): documental e conceitual.

Circunscrição documental, por um lado, porque buscam a troca de presentes primariamente em fontes que descrevem relações intra-aristocráticas; conceitual, por outro lado, porque ambos caracterizam a reciprocidade como o fundamento da troca de presentes, ainda que suas análises sejam restritas ao escopo social onde a reciprocidade é a norma. Ao fim, o processo é circular: a ideia conceitual (troca de presentes fundada na reciprocidade) sustenta/é sustentada e fortalece/é fortalecida por uma seleção documental específica (relações intra-aristocráticas). Esse processo circular é sintetizado brevemente por Chris Wickham ao notar que "ainda que nossa evidência sobre reciprocidade (como a maior parte das coisas) enfoque as elites, e exclua a participação do campesinato dependente, nós podemos assumir com segurança que na sociedade camponesa reciprocidade (e política, e honra) eram tão normais quanto na sociedade de elite" (WICKHAM, 2010, p. 244). Dessa forma, a reciprocidade é a norma projetada sobre a "sociedade camponesa", ainda que nossa evidência, supostamente, exclua esse grupo de nossas considerações. Essa dupla circunscrição 
(documental e conceitual) resulta em uma circunscrição temática: troca de presentes intraaristocrática. $^{3}$

O presente artigo desafia essa dupla circunscrição ao argumentar que a troca de presentes não é restrita nem às relações aristocráticas nem a seu aspecto recíproco. Se aristocratas podem de fato se engajar em negociações usando "um repertório de formas culturais existentes para definir e redefinir a natureza das transações, identidades e relações" (ALGAZI, 2003, p. 12), nós deveríamos dirigir nossas atenções também para os elementos de diferenciação de acesso e uso desse repertório. Se a troca de presentes é mais do que uma relação intra-aristocrática e recíproca, nossas análises são parciais enquanto não puderem examinar as relações construídas sobre e fortalecidas pela ideia de que todos os dons devem ser reciprocados, ainda que nem todos sejam capazes de fazê-lo.

Nesse enquadramento, reciprocidade significa mais do que simplesmente dar algo de volta, mas requer que se dê o mesmo ou mais (MAUSS, 2003, p. 305). ${ }^{4}$ Definir o que é o mesmo, mais, e menos é precisamente o tipo de negociação que Algazi menciona, mas uma que é intrinsicamente desigual e fundamentalmente conflitiva. Se perdemos de vista a dimensão intrinsicamente conflitiva da troca de presentes (mas, não obstante, fundada em seu aspecto recíproco, transformamos o conceito de um "fato social total" (MAUSS, 2003, p. 314) em pouco mais que um sinônimo hiper-teorizado do conceito de patronato (da elite) (SALLER, 2002; WALLACE-HADRILL, 1989).

\section{Estudos de Caso}

Hagiografias são um tipo complexo de fonte histórica: são forjadas em meio a topoi, em diversos casos suas narrativas são um diálogo em curso com outros textos do cânone cristão, difíceis tradições manuscritas, objetivos políticos explícitos (e implícitos) e, acima de tudo, existe um consenso geral que são pouco confiáveis como fontes históricas (VELÁZQUEZ SORIANO, 2007, p. 36-43; WOOD, 1999a, p. 100). Esse consenso, contudo, não implica a recusa do historiador em analisar essa documentação, mas que isso deve ocorrer através do emprego de uma metodologia específica. Dessa forma, utilizaremos uma metodologia esboçada por Ian Wood que consiste na identificação e localização (cronológica

\footnotetext{
${ }^{3}$ Esse diagnóstico apresenta uma tendência geral, ainda mais marcada pelas exceções a ela, tanto no campo da antropologia (GODELIER, 2001) quanto na medievalística, (PASTOR; RODRÍGUEZ LÓPEZ, 2000; BERNARDO, 1995).

4 "Dar é manifestar superioridade, é ser mais, mais elevado, magister, aceitar sem retribuir, ou sem retribuir mais, é subordinar-se, tornar-se cliente e servidor, ser pequeno, ficar mais abaixo (minister)" (MAUSS, 2003, p. $305)$.
} 
e geográfica) de "conjuntos de textos hagiográficos" (WOOD, 1999a, p. 105). Ao fazê-lo, estamos menos interessados nos debates teológicos que podem emergir dentro de um mesmo conjunto e mais em propor que esses "conjuntos hagiográficos" devem apresentar uma imagem coerente do mundo social e das práticas sociais, logo, apresentam a possibilidade de serem investigados por nós (PACHÁ, 2014).

\section{a) Vita Sancti Aemiliani (VSA)}

Bráulio, Bispo de Saragoça, escreveu a Vita Sancti Aemiliani entre os anos 635-640 e a dedicou ao seu irmão, o presbítero Fronimiano (VÁZQUEZ DE PARGA, 1943, p. X; OROZ, 1978, p. 178). ${ }^{5}$ Escrita em meio aos modelos narrativos disponíveis, a vita narra a resposta de Emiliano (um pastor de ovelhas) ao chamado divino e os diversos milagres que ele desempenhou. O cenário geográfico inicial da vita é o norte da península, mais especificamente a região do Berceo e as montanhas vizinhas (onde ele realiza seus primeiros milagres e atrai algumas multidões) (OROZ, 1978, p. 186-190). ${ }^{6}$ De acordo com Espinosa Ruiz, Emiliano deve ter vivido nos anos entre 473 e 574, um período suficientemente próximo à redação da vita para que Bráulio fosse capaz de apontar alguns discípulos de Emiliano como suas fontes (ESPINOSA RUIZ, 2013, p. 81; OROZ, 1978, p. 178).

Sob o título "expulsa um demônio da casa de um senador", o hagiógrafo narra que na casa de um grande aristocrata chamado Honorius vivia "um demônio extremamente nocivo e sedicioso" que "todos os dias perpetrava algum ato vil e repugnante". ${ }^{7}$ Tão logo o "senhor da casa sentava-se à mesa para um banquete, o espírito impuro colocava ossos de animais mortos e, mais vezes ainda, lixo nos seus pratos" e "à noite, quando os habitantes estavam dormindo, ele roubava as roupas de homens e mulheres, pendurando-as no teto"8 Angustiado por essa terrível situação, Honório envia seus mensageiros para trazer Emiliano até à casa, "enviando carruagens para seu transporte". O santo, "importunado por suas súplicas”, aceita ir à casa

\footnotetext{
${ }^{5}$ Fear (1997, p. 15) interpreta “irmão" como um laço espiritual.

${ }^{6}$ De acordo com Espinosa Ruiz (2013), 'villa Vergegio' estaria localizada na região contemporânea do Berceo.

7 “De daemone expulso a domo Honoris senatoris Parpalinensis" (OROZ, 1978, p. 200).

8 "Sceleratissimum seditionariumque, domus Honorii senatoris daemonem sustinebat, qui eousque monstruosissime domini illius incubabat ut foedissima quaedam turpissimaque quotidie inferebat, nec daemonicolam quispiam sustinere poterat; denique saepe dominus domus quum causa conuiuii fuisset accubitatus, ferculis eius, animalium ossa mortuorum et plerumque stercora, inferebat spiritus inpurus; saepe uero, nocturno tempore, datis omnibus in quiete, uestimenta uirorum ac mulierum subtrahens, ueluti quaedam uclamine foeditatis suspendebat e tectis" (OROZ, 1978, p. 200).
} 
“mas o fez à pé, não em uma carruagem". ${ }^{9}$ Em Parpalines, Emiliano ordena um jejum e, no terceiro dia põe em fuga o combativo demônio.

Algumas seções após, o hagiógrafo narra que juntamente com a expansão de sua fama, "não faltavam multidões que vinham vê-lo [Emiliano] diariamente" e "como era seu direito, ele compelia os visitantes de seu oratório a ficarem mais e se refrescarem com sua caridade". ${ }^{10}$ Quando seu servidor disse a Emiliano que "não havia mais nada para eles comerem", ele admoestou o homem e "rezou para que Cristo providenciasse o alimento necessário". ${ }^{11}$ Antes que ele pudesse terminar sua prece, "carroças generosamente carregadas com comida e enviadas pelo senador Honório entraram pelos portões". ${ }^{12}$ Emiliano agradeceu então não à Honório, mas ao "Criador do Mundo, por ter ouvido sua prece", "separou uma quantidade de comida suficiente para seus convidados e determinou que o resto fosse guardado para aqueles que pudessem chegar mais tarde". ${ }^{13}$

Enquadradas através da troca de presentes, essas duas narrativas nos oferecem um caso clássico da síntese maussiana dos três temas do dom: "a obrigação de dar, a obrigação de receber e reciprocar" (MAUSS, 2003). Ou seja, todo dom requer um contra-dom. A relação entre Emiliano e Honório exemplifica cada um desses temas da troca de presentes: dar (o exorcismo do domus), receber (aqui ainda mais forte, uma vez que é Honório que pede ao santo que o ajude) e reciprocar (Honório envia a Emiliano os carros carregados com comida). Essa relação intra-aristocrática é desigual por um breve período (como são a maior parte das trocas de presentes), mas seu resultado final é uma equalização. $\mathrm{O}$ jogo de poder entre os dois aristocratas é expresso, por um lado, no pedido de Honório e na recusa (inicial) de Emiliano; por outro lado, quando o senator envia sua carruagem para trazer o santo até Parpalines e ele recusa, escolhe, ao contrário, caminhar.

Sendo dar uma das três obrigações recíprocas, não é de fato uma opção para o santo a recusa ao pedido de Honório. As recusas iniciais e súplicas que se seguem desempenham o papel de explicitar a relação recém-estabelecida. Devemos notar também que, ainda que seja Honório a solicitar o auxílio do santo, ele o faz através de seus mensageiros. Da mesma

\footnotetext{
9 “...dirigens subsidia uehiculorum. Veniunt nuntii, implorant ut accedat et qua ope posset daemonem pellat; tandem, fatigatus precibus, ad ostendendam dei nostri uirtutem, pedibus suis, non uehiculo, est profectus" (OROZ, 1978, p. 200).

10 "Ut apud hominem dei, fama sanctitatis illius diuulgante, non deerant cotidie aduentantium cateruae, iure suo conpulit oppido hospites moras innectere et caritatis intuitu semetipsos reficere" (OROZ, 1978, p. 204).

11 “...nuntiat nihil superesse quod possint prandere” (OROZ, 1978, p. 204).

12 "Necdum intentionem finierat et ecce subito uehicula copiose onusta, ab Honorio senatore directa, ianuam intrant” (OROZ, 1978, p. 204).

13 "Dilectus dei directa suscipit, et, gratias rerum creatori, exauditus, persoluit: inuitatis sufficientes cibos adponit; reliquum conseruari superuenientibus praecepit” (OROZ, 1978, p. 204).
} 
forma, a recusa inicial do santo é direcionada ao pedido de Honório, mas expressa a seus mensageiros. Assim, as súplicas que incomodam Emiliano são dos mensageiros de Honório, não do senator. É esse mecanismo sutil - a mediação dos mensageiros - que torna possível para ambos os atores demonstrarem suas duras posições. Sua relação torna-se desigual quando Emiliano "põe em fuga" o demônio que assombrava o domus de Honório. Contudo, essa desigualdade é rapidamente superada quando, apenas algumas seções após essa narrativa, Honório envia as carroças carregadas com comida para Emiliano que, por sua vez, aceita o contra-dom.

Aqui nós temos dois agentes negociando o dom, seus limites e os meios com os quais ele será expresso: Emiliano é capaz de recusar primeiro e aceitar depois (mas reconhecendo Deus como o verdadeiro doador); Honório tenta reduzir a desigualdade da relação enviando a carruagem para ajudar o santo. A negociação permeia cada momento da relação (ALGAZI; GROEBNER; JUSSEN, 2003). Essas iniciativas de antecipação (pedir e tentar disfarçar o pedido como uma oferta, agradecer à um terceiro sujeito etc.) precisam ocorrer uma vez que o uma troca de presentes é sempre uma questão delicada. O tema da dominação está sempre presente, mesmo que na maior parte das vezes apenas pressuposto: para Emiliano e Honório, pedir ao outro que conceda esse tipo de dom é um ato ao qual se recorre quando não há nenhuma alternativa. Essa relação, enquadrada pela troca de presentes, é estabelecida e desenvolvida em dois momentos de grande necessidade para ambos.

A estrutura do segundo milagre é então bastante explícita: tratava-se de um momento de grande perigo para Emiliano, que deveria ser capaz de alimentar a multidão que o cercava. Devemos lembrar que a manutenção do estatuto do santo estava diretamente fundada na sua capacidade cotidiana de intervir na esfera do sagrado, i.e., sua capacidade de realizar milagres. Sem essa, seus poderes de atração e controle seriam radicalmente reduzidos. Após o contra-dom de Honório, a relação entre ele e Emiliano é equalizada, logo, minando a posição superior do santo em relação ao senator. Ambos os atores são capazes de realizarem suas obrigações recíprocas. Mas é através dessa mesma ação que a relação desigual entre Emiliano e a multidão pode ser sustentada.

Essa multidão é um terceiro sujeito (coletivo) que existe em paralelo à relação entre Emiliano e Honório. Um sujeito coletivo que é definido por uma variedade de palavras, como multidão (caterua, multitudo), povo (populi) e os pobres (pauperes). Aqui encontramos duas pistas sobre a condição social dessas pessoas: por um lado, a região do vale do Alto Ebro onde Parpalines estava localizada é caracterizada como um ambiente rural (CASTELLANOS, 1998, p. 51; ESPINOSA RUIZ, 2013, p. 96); por outro lado, a indicação de Santiago 


\section{Notandum 43 jan-abr 2017 - CEMOrOC - Feusp / IJI-Univ. do Porto DOI: http://dx.doi.org/10.4025/notandum.43.1}

Castellanos que, através de um processo de polarização social, "a quase totalidade da população que é mencionada nas fontes e não é identificável entre os potentes está em uma situação de dependência real para com eles." (CASTELLANOS, 1998, p. 83). Dessa forma, não é abusivo caracterizar essa multidão como camponeses empobrecidos, enfatizando que enquanto um sujeito coletivo, individualmente eles podem ter diversos estatutos jurídicos (servi, ingenui, liberti, fugitivi etc). Enquanto camponeses empobrecidos é por viverem ao redor do santo que essas pessoas encontravam as condições de acesso para sua reprodução material e social. Em outra passagem da mesma hagiografia, uma multidão (turbae, pauperes) se dirige ao santo "pedindo por sua costumeira esmola". ${ }^{14}$ Sem nada para dar naquele momento, o santo cortou as mangas de sua túnica e as deu juntamente com sua capa. ${ }^{15} \mathrm{Um}$ desses pauperes, "que era mais impertinente que os demais, como é costume entre os mendigos [mendicantium]" adiantou-se aos demais e vestiu-se com o presente do santo. Por seu ato, foi espancado pelos outros. ${ }^{16} \mathrm{O}$ elemento mais importante dessa narrativa é a natureza recorrente dos presentes do santo para esses mendigos, uma vez que esses pedem por sua usual, e corretamente antecipada, subvenção. É exatamente por isso que o santo precisa dar alguma coisa, mesmo que apenas as mangas de sua túnica e sua capa. De acordo com Martín Cerezo e Julio Escalona, mendicantium indica aqui uma relação de dependência pessoal frouxa mas, não obstante, real (CEREZO; MONGE, 1988, p. 209).

Encontramos exatamente a mesma lógica em funcionamento quando, em outra ocasião, uma multidão vai até o santo e ele não dispõe de vinho. ${ }^{17}$ Através de sua relação com Deus, o santo é capaz de realizar um milagre e "uma grande multidão ficou completamente satisfeita, segundo dizem, com apenas um sextario de vinho". ${ }^{18}$ Em conjunto, esses casos demonstram que essas relações entre o santo e a multidão são perenes, sempre reproduzidas por ambas partes e envolvendo elementos de sua reprodução material e ideal. As relações de dependência pessoal, conforme a caracterização de Abilio Barbero e Marcelo Vigil, estavam fundadas nas ideias de fides/fidelis e obsequium/servitium. O Concílio de Mérida (666) determinou que quando um presbítero de uma igreja rural fosse transferido pelo bispo para a Catedral, o primeiro seria responsável por prover comida e roupas para o novo clérigo a cargo da igreja rural (BARBERO; VIGIL, 1978, p. 102; VIVES, 1963, p. 333-ss). Para esses

\footnotetext{
14 “...poscentes consuetam subsidii stipem...”(OROZ, 1978, p. 202).

15 “...ipse seu deficiente seu non ocurrente quod prorogari deberet, ab ingenita non deficiens pietate, praecidens manicas suae tunicae, cum pallio quo utebatur, obtulit benignus" (OROZ, 1978, p. 202).

16 "Tunc unus ex cunctis inportunior, ut mos est mendicantium, caeteris aliis praeueniens, accepit; acepta induit" (Idem).

17 "Contigit conuenire frequentiam populi, quando parum beato uiro esset uini" (OROZ, 1978, p. 204).

18 “....ut aiunt e sextario affatim satiata est ingens multitudo" (OROZ, 1978, p. 204).
} 
autores, os termos fides/fidelis e obsequium/servitium são aplicados como equivalentes tanto nos cânones religiosos quanto na legislação civil (BARBERO; VIGIL, 1978, p. 102-103).

Ambos os casos acima (na VSA) são relações estruturadas pela troca de presentes. Como em toda troca de presentes, essa relação é estabelecida por um ato de doação e a dívida que o segue. Dessa forma, é sempre uma relação desigual. Mas a principal questão aqui é a dilação temporal do segundo ato de doação: se, por um lado, esse segundo ato é realizado pela mesma parte que doou primeiro, dívida pode se tornar dependência para aquele que recebe novamente; se, por outro lado, os papéis são inversos e o primeiro recipiente é agora o doador (de um dom equivalente), nós temos troca de presentes recíproca - uma vez que ambas partes são doadoras e recipientes - e balanceada - os dons são equivalentes. O principal produto dessa troca é uma relação mais forte entre as duas partes, ambas as quais reconhecem o poder da outra (para dar) e mantém o seu próprio (ao reciprocarem). Logo, a relação entre Emiliano e Honório na VSA é troca de presentes recíproca e balanceada.

A segunda relação, entre Emiliano e a multidão, tem um resultado diferente. Já demonstramos como as relações estabelecidas pelo santo e a multidão tem uma dinâmica recorrente, mas sempre com Emiliano mantendo seu papel social de doador. A lógica aqui é a mesma que na relação entre Emiliano e Honório, mas o momento de equalização e balanceamento não existe. A relação entre Emiliano e os camponeses empobrecidos não tem reciprocidade como seu resultado nem equilíbrio como seu produto. Em oposição, encontramos apenas a primeira sequência (o santo como doador) sendo repetida indefinidamente. Os camponeses nunca são capazes de assumirem os papéis de doadores em sua relação com o santo. Logo, essa relação é troca de presentes não-recíproca e desigual: seu resultado só pode ser a dependência pessoal.

\section{b) Vitas Sanctorum Patrum Emeretensium}

O conjunto anônimo intitulado Vitas Sanctorum Patrum Emeretensium (VSPE) é uma coleção de hagiografias cujas narrativas se estendem de meados do século VI até a primeira metade do século VII. Escrita entre 633 e 638, a VSPE divide-se em duas partes: a primeira aborda a vida de pessoas que viveram em Mérida (ou na região circundante) - o eixo geográfico da vitae - e envolve diversos relatos de milagres; a segunda parte narra as vidas de cinco bispos subsequentes de Mérida durante o período enquadrado pela vitae: Paulo, Fidel, Masona, Inocêncio e Renovatus (VELÁZQUEZ SORIANO, 2008, p. 11-15; PANZRAM, 2010). 
A cidade de Mérida não é apenas o eixo geográfico da vitae, mas ela própria uma grande personagem da hagiografia. Como uma das maiores cidades da Hispania desde a sua fundação no governo de Augusto, o desenvolvimento da cidade é particularmente incomum (COLLINS, 1980, p. 194). Mérida foi dotada com um conjunto de edifícios cívicos durante o Império Romano e, de acordo com Roger Collins, mesmo no século VI era possível discernir um período de construção e reconstrução. Segundo o autor:

A importância desse programa de edificações reside não tanto no fato de que ele aconteceu, mas em como foi possível que isso ocorresse. O ponto crucial é que ele foi resultado do trabalho dos bispos da cidade e, além disso, era parte de um extenso sistema de patronato muito mais amplo. (COLLINS, 1980, p. 195)

Essa especificidade - um conjunto de riqueza com vida cívica dinâmica caracterizaria Mérida como pertencente "a um mundo de cidades mediterrânicas, com contatos longínquos" (WOOD, 1999b, p. 194).

Por um lado, o papel da vida cívica, especialmente em sua reprodução pelas famílias aristocráticas da Antiguidade Tardia por toda a Península Ibérica é bem conhecida; por outro lado, no contexto de grande ruralização, as cidades se tornaram pólos de atração por diversos motivos. De acordo com Luis García Moreno, a articulação desses dois elementos fizeram das cidades o locus privilegiado da "clara tendência de aristocracias terratenentes de caráter urbano para ocuparem posições-chave na administração do Estado ou na hierarquia eclesiástica" (GARCÍA MORENO, 1989, p. 268). Quando não era possível encontrar um poder público que funcionasse como a liderança da cidade, os bispos emergiram como as figuras capazes de organizarem acordos e resistências (BROWN, 2013, p. 106-111). Nesse período, por toda a Europa Ocidental o episcopado se inseriu um posições-chave na administração das cidades; um processo no qual se transformou em uma posição extremamente disputada.

Uma das figuras de liderança urbana em Mérida era o bispo Masona - para Isabel Velázquez ele é mesmo a principal personagem das VSPE (VELÁZQUEZ SORIANO, 2008, p. 114 n. 1). Caracterizado pela virtude da generosidade, Masona era, sobretudo, um prolífico doador (MAYA SÁNCHEZ, 1992, p. 48-50). Ele era também um construtor e fundador de muitos e ricos monastérios e até mesmo "construiu um número ainda maior de basílicas de maravilhosa aparência”. Em adição aos monastérios e basílicas ele construiu um xenodochium (um edifício destinado a prover abrigo e ajuda à peregrinos e doentes), o qual foi ricamente 


\section{Notandum 43 jan-abr 2017 - CEMOrOC - Feusp / IJI-Univ. do Porto DOI: http://dx.doi.org/10.4025/notandum.43.1}

dotado com um grande patrimônio. ${ }^{19}$ Masona também ordenou que o xenodochium deveria receber "metade de todas as rendas [...] de todo o patrimônio da Igreja". ${ }^{20}$

Através do xenodochium, Masona estabeleceu relações não apenas com a aristocracia local, mas com todos os níveis sociais em Mérida. Ele teria comandado os médicos que serviam no xenodochium para buscarem e trazerem todos os doentes de Mérida até o edifício, "seja ele escravo ou livre, cristão ou judeu". ${ }^{21} \mathrm{O}$ xenodochium era também um lugar onde os camponeses da região (rusticis de ruralibus) e cidadãos de Mérida podiam receber alguns bens (como vinho, azeite e mel). ${ }^{22}$ Sua generosidade, seu hagiógrafo se apressa em enfatizar, não estava restrita aos seus irmãos e amigos mas era, acima de tudo, dirigida aos pobres. ${ }^{23}$ Masona, diz o hagiógrafo, "excedia-se na virtude magnânima de dar, e não de receber", e "Deu muito e nada tomou para si, mas voluntariamente atendeu aos pedidos de todos" (MAYA SÁNCHEZ, 1992, p. 53). Mesmo o hagiógrafo reconhecia a posição privilegiada do bispo nos circuitos de intercâmbio: “[Masona] deu muitos presentes, mais favores, enriqueceu a todos através da munificência de seus dons e por essa munificência era tido como um grande homem.”. ${ }^{24}$ Essa posição privilegiada é ainda mais explícita na seguinte cena:

De fato, em seu tempo eram [os dependentes da Igreja] tão ricos que no dia mais sagrado da Páscoa ele [Masona] saia em direção à igreja cercado por muitos meninos vestindo capas de seda como se estivessem na presença de um rei, e com essas indumentárias, algo que naqueles dias ninguém podia ou pensava fazer, eles iam na sua frente e prestavam a devida homenagem a ele. ${ }^{25}$

Enfatizando uma vez mais que as relações do bispo não estavam restritas aos circuitos aristocráticos da troca de presentes, o hagiógrafo tenta destacar tanto a generosidade do bispo

\footnotetext{
19 “...episcopatus sui monasteria multa fundauit, prediis magnis locupletauit, baselicas plures miro opere construxit et multas Ibidem Deo animas consecrauit". "Deinde xinodocium fabricauit magnisque patrimoniis ditauit..." (MAYA SÁNCHEZ, 1992, p. 48-50).

20 "Sed his omnibus beneficiis adiciens maiora precepit medicis ut sagaci sollicitudine gererent curam ut de omnibus exeniis ab uniuersis actuariis ex omni patrimonio eclesie in atrium inlatis medietatem acciperent, ut eisdem infirmis deferrent" (MAYA SÁNCHEZ, 1992, p. 51).

21 "...ut cuncte urbis ambitu medici indesinenter percurrentes quemquumque seruum seu liberum, Xpianum siue Iudeum" (MAYA SÁNCHEZ, 1992, p. 50).

22 "Si quis uero de ciuibus urbis aut rusticis de ruralibus ad atrium ob necessitate accessisset, licorem uini, olei uel mellis...” (MAYA SÁNCHEZ, 1992, p. 50).

23 "seruulis eclesie" (MAYA SÁNCHEZ, 1992, p. 52).

24 "Donabat multa, largiebat plurima, ditabat munificentia uniuersos beneficiis et munificentia magnus habebatur" (MAYA SÁNCHEZ, 1992, p. 53).

25 "Ita nimirum temporibus eius ditati sunt, ut in diem sacratissimum Pasche, quum ad eclesiam procederet, plurimi pueri clamides olisericas induentes quoram eo quasi quoram rege incederent et, quod his temporibus nullus poterat, nullus presummebat, huius indumentis amicti ante eum deuitum deferentes obsequium pergerent" (MAYA SÁNCHEZ, 1992, p. 53).
} 
quanto o poder que essa subentendia, equalizando-o ao cortejo real. O tipo de poder alcançado pelos bispos, como Masona, deve ser visto em um contexto tardo-antigo como a emergência de um novo tipo de liderança civil nas cidades. Cenas como essa enfatizam a transformação do papel dos bispos de líderes religiosos em líderes civis. As passagens mencionadas acima caracterizam Masona não apenas como um grande bispo, mas também como um grande aristocrata, ainda que eclesiástico.

Como bispo de Mérida, Masona era responsável pela administração de todo o patrimônio da Igreja na região (BARBERO; VIGIL, 1978, p. 58-69). Na mesma VSPE narrase que décadas antes esse patrimônio cresceu imensamente através da doação de um casal de aristocratas a um antecessor de Masona, o bispo Paulo. A doação era a retribuição ao Bispo Paulo por ter curado e salvado a vida da mulher de um senator. O patrimônio doado, que jamais é detalhado na hagiografia, mas o qual deveria ser composto por diversas propriedades rurais, permaneceu como propriedade pessoal de Paulo até sua morte, sendo então herdado, também como propriedade pessoal, por seu sobrinho, Fidel (DÍAZ MARTÍNEZ, 1998, p. 260-261). A aceitação de Fidel como o sucessor de Paulo no episcopado pelos clérigos de Mérida é diretamente atribuída a sua posse legítima desse patrimônio e a promessa de que, após sua morte, este passaria a integrar o patrimônio da Igreja (MAYA SÁNCHEZ, 1992, p. 36). Um dos elementos que esclarece uma situação como essa é o destaque na hagiografia da extensão desse patrimônio, enfatizando que Paulo teria se tornado mais rico que todos os outros aristocratas da Lusitania. ${ }^{26}$ Após a doação, até mesmo o patrimônio da Igreja de Mérida é caracterizado como incomparavelmente menor que o de Paulo. ${ }^{27}$ Nas VSPE, a história dos bispos de Mérida está intimamente vinculada com as diversas transferências e usos desse patrimônio. Masona, o sucessor imediato de Fidel, é então um aristocrata extremamente poderoso. Ainda que as propriedades mencionadas não constituam sua propriedade pessoal, ele é o administrador de toda a propriedade da Igreja na região.

De acordo com Abilio Barbero e Marcelo Vigil, os reinos pós-Romanos testemunharam o resultado de um processo multi-secular de unificação das figuras do dominus e patronus na mesma pessoa. Esse processo (cuja origem pode ser encontrada nas transformações gerais da economia Romana no século II) uniu "a dependência econômica ou material à pessoal ou extra-econômica" (BARBERO; VIGIL, 1978, p. 22). O dominus como

\footnotetext{
26 "Tanta namque illis inerat copia rerum, ut nullus senatorum in prouincia Lusitanie illis repperiretur locupletior" (MAYA SÁNCHEZ, 1992, p. 30).

27 "Et qui peregrinus nicilque habens aduenerat factus est cunctis potentibus potentior in tantum ut omnis facultas eclesie ad conparationem bonorum illius pro nicilum putarentur” (MAYA SÁNCHEZ, 1992, p. 30).
} 
proprietário da terra e o patronus como o protetor pessoal teriam sido, na sua origem, duas formas diversas de relação com o campesinato dependente. Conforme o processo se desenvolveu, ambos os papéis teriam sido unificados na pessoa de um único aristocrata, agora um dominus e patronus. Para Barbero e Vigil, já no I Concílio de Braga (400) encontramos evidências dessa unificação de papéis na proibição de ordenar como clérigos aqueles que fossem dependentes de alguém caso essa relação não fosse previamente rompida. Essas relações são caracterizadas como relações com senhores e patronos - domini vel patroni (BARBERO; VIGIL, 1978, p. 23; VIVES, 1963, p. 22). Como um grande aristocrata, isto é, como um grande proprietário de terras, Masona seria uma das figuras representadas por essa unificação do dominus com o patronus. As relações entre Masona e seus dependentes pessoais na cidade de Mérida e nas propriedades rurais circundantes eram, portanto, fundadas tanto em seu papel como um grande patronus quanto como um poderoso dominus.

Para Barbero e Vigil a mesma terminologia era usada na legislação visigoda para descrever as relações dependência em todos os níveis da organização social (BARBERO; VIGIL, 1978, p. 189). Quando compreendidos dessa forma, os pares conceituais obsequium/servitium e fidelis/infidelis são absolutamente centrais: eles "designavam as relações de dependência e a ruptura dessa relações entre servos, libertos, livres encomendados, clérigos e membros da nobreza, tanto com os senhores privados quanto com a Igreja e o monarca" (BARBERO; VIGIL, 1978, p. 169-170). Uma das obrigações dos aristocratas (laicos ou eclesiásticos) em troca do obsequium/servitium era prover a vestimenta e alimentação de seus dependentes, o que é atestado tanto na documentação eclesiástica quanto civil (BARBERO; VIGIL, 1974, p. 102-103). É exatamente esse tipo de relação que encontramos nas VSPE entre Masona e o camponeses, libertos e escravos que buscam sua ajuda no xenodochium, ou quando esses o honram compondo seu cortejo. Esse tipo de relação é ainda mais explícita quando o hagiógrafo nota que esses mesmos atores iam ao xenodochium pedindo por "uma medida de vinho, azeite ou mel", dons que podiam ser entregues pelo próprio Masona. ${ }^{28} \mathrm{O}$ que encontramos em todas essas passagens são evidências de relações de dependência pessoal nas quais Masona estava cumprindo seu papel como dominus e patronus. Em meio às representações sociais da sociedade visigoda é

\footnotetext{
28 "Si quis uero de ciuibus urbis aut rusticis de ruralibus ad atrium ob necessitate accessisset, licorem uini, olei uel mellis a dispensantibus poposcisset et uasem paruulum in quo lebaret exibuisset et eum uir sanctus uidisser, ut erat semper obtutu gratus, iucundi uultu, mox ipsud uasculum confringi et ut maiorem deferret precipiebat" (MAYA SÁNCHEZ, 1992, p. 51).
} 
bastante claro que o único ato que poderia ser esperado desses dependentes era que se comportassem como fideles e fornecessem à Masona seu obsequium/servitium.

As relações as quais Masona desenvolveu ou fortaleceu, através do xenodochium (tanto com os habitantes da cidade quanto com camponeses) ou como um grande senhores precedido por seu cortejo ricamente vestido, aparecem como as relações entre um aristocrata poderoso e seus dependentes pessoais. Mesmo que não possamos esquecer os ideais cristãos de piedade e caridade, é necessário reconhecer que esses ideais são históricos, e apenas podem ter existência efetiva no quadro geral dessa especificidade histórica.

As passagens supracitadas nos fornecem imagens de trocas de presentes entre santos e um grupo heterogêneo. Esse grupo é visível na multidão de pobres que se reúne em torno de Emiliano e têm sua reprodução material possibilitada pelas ações do homem santo (inclusive sua relação com o senator Honório). Eles são a multidão que perturba Emiliano em Berceo e, novamente, em seu refúgio no Monte Dicertius; os pedintes que vêm até ele "pedindo por sua costumeira esmola" e a multidão que o cerca quando ele não dispunha de suficiente vinho. ${ }^{29}$ As palavras latinas para descrever esse grupo são diversas: caterua, multitudo, mendicantes, populi e pauperes.

Assim como Emiliano, Masona era um homem santo que entrava em relações com todo o espectro social; com outros aristocratas e com esse grupo heterogêneo menciona acima. Através do xenodochium, ele foi capaz de superar o contexto imediatamente urbano de Mérida e criar (ou reproduzir) essas relações com os camponeses vizinhos. Na vita de Masona esse grupo heterogêneo é descrito por termos como rustici, seruus, liberum, seruulis eclesie (MAYA SÁNCHEZ, 1992, p. 50-54). Em ambas histórias, o principal elemento desse grupo heterogêneo é sua falta de um estatuto aristocrático. Em cada um dos casos mencionados, jamais são individualizados, sendo sempre descritos como um agente social coletivo. Conforme já mencionamos, Cerezo e Escalona analisaram cada um desses termos na VSA e os classificaram como formas variadas de dependência pessoal, algumas estreitas, outras mais frouxas (CEREZO; MONGE, 1988). Construir uma tipologia das formas de dependência é um passo fundamental, mas a principal questão permanece: como desvelar os mecanismos que sustentam essas relações de dependência pessoal?

Nossa hipótese, conforme discutido acima, é que nessas relações entre um santo e esse sujeito coletivo o elemento fundamental da troca de presentes não é reciprocidade, mas

\footnotetext{
29 “uidet inpedimento sibi fore hominum ad se concurrentium multitudinem'; 'eousque fama sanctitatis eius percrebuit ut in notitia paene omnium perueniret"; "poscentes consuetam subsidii stipem". (OROZ, 1978, p. $188,190,202,204)$
} 
dominação. Isso não significa que a reciprocidade não desempenha um papel fundamental na troca de presentes. Ao contrário, a reciprocidade existe como o complemento da dominação. Reciprocidade não é o único elemento fundamental da troca de presentes justamente porque é absolutamente inócua sem o seu complemento, dominação. A forma tanto da reciprocidade quanto da dominação varia em cada sociedade, mas sua intercessão na troca de presentes é uma constante.

Essas relações de dependência pessoal são duradouras. O sentido específico da reciprocidade nessas relações era determinado pela insuficiência do obsequium ou servitium desses indivíduos para completar a troca de presentes: reciprocidade aqui não significa dar algo em retorno, mas dar o mesmo ou mais (MAUSS, 2003, p. 305). O elemento principal aqui não é que os camponeses (ou a multidão) não possa dar nada em troca, mas que eles necessariamente entregam menos do que receberam. Isso acontece não apenas porque eles não têm acesso a bens de prestígio etc., mas porque dispõem de uma posição (social) inferior em relação ao santo. A desigualdade era inerente à troca de presentes e esses agentes inferiores não podem "completar" o circuito de intercâmbio. Troca de presentes era um mecanismo para criar, reproduzir, expressar e reforçar as relações de dependência pessoal.

Em relação a Emiliano e Masona precisamos indagar quais são os resultados da troca de presentes quando alguém precisa receber mas não pode reciprocar. A única coisa com a qual a multidão podia retribuir a Emiliano ou Masona como contra-dom pela comida (ou roupas, proteção espiritual, milagres, curas etc) era sua fidelidade e obediência (fides), ou seja, a realização de serviços (obsequium/servitium) para eles. Mas esses serviços não tornam o circuito do intercâmbio completo, eles apenas reproduzem a mesma relação de uma dívida eterna que jamais pode ser paga (nas condições existentes).

Esses serviços poderiam ser realizados de diversas maneiras. Do auxílio direto ao homem santo (algo explícito nessas hagiografias, mesmo quando o santo está em seu "período eremítico") ao estabelecimento em uma comunidade monástica ou a entrega de bens para o santo e seus seguidores (DÍAZ Y DÍAZ, 1974, p. 114-116; OROZ, 1978, p. 206-208). Conforme já vimos, a relação entre Emiliano e seus seguidores ou entre Masona e seus clientes em Mérida não era diferente daquele entre um grande aristocrata e seus dependentes pessoais. Em meio a todas essas possibilidades, a questão principal é que através de um relação articulada pela troca de presentes, esses indivíduos entravam em relações de dependência pessoal com o santo. "Dons entre iguais", conforme indicado sucintamente por Ian Wood, "certamente tinham um papel na criação e manutenção de laços de amizade, amiticia, os quais se encontravam no cerne da sociedade aristocrática" (WOOD, 2000, p. 
303). Conforme indicamos acima, entre desiguais, como aristocratas (mesmo os eclesiásticos) e pauperes ou camponeses, dons desempenhavam um papel na criação de desigualdade e dependência. A Alta Idade Média Ibérica não foram diferentes. A troca de presentes foi um mecanismo central no processo de expansão e generalização das relações pessoais de dependência (BARBERO; VIGIL, 1978, p. 150-200).

\section{c) Vita Sancti Fructuosi}

A Vita Sancti Fructuosi (VSF) foi escrita algumas décadas depois também por um autor anônimo (DÍAZ Y DÍAZ, 1974, p. 13-23). O texto é composto por duas seções independentes, as quais foram posteriormente fundidas. $\mathrm{O}$ texto mais antigo vinculado ao norte da península ibérica e o mais novo ao sul. Díaz y Díaz indica que a vita deve ter sido escrita na região de Braga entre 670 e 680; Codoñer Merino refina esse argumento ao observar que a fusão das duas seções provavelmente ocorreu, no máximo, até 690 (CODOÑER MERINO, 1984, p. 190; DÍAZ Y DÍAZ, 1974, p. 14-15). A vita, portanto, deve ter sido escrita logo após a morte do santo (665) (CODOÑER MERINO, 1984, p. 190; DÍAZ Y DÍAZ, 1974, p. 14-15).

Frutuoso é descrito por seu hagiógrafo como "nascido de uma família gloriosa e vinculada com reis", sendo firmemente inscrito no topos que relaciona o santo a uma origem aristocrática (CODOÑER MERINO, 1984; DÍAZ Y DÍAZ, 1974). Seu “momento de revelação" ocorreu cedo em sua infância, mas apenas após a morte de seus pais Frutuoso iniciou sua vida religiosa. Descrito tanto como um eremita quanto como um irrefreável fundador de mosteiros, é nessa segunda característica que encontraremos algumas respostas para nossas questões.

Após um período formativo sob a autoridade do Bispo Conâncio, Frutuoso retornou ao seu "lugar de solidão" (os vales montanhosos de Bierzo, no noroeste da Península), onde foi "inspirado pelo Senhor" e prometeu construir um monastério ainda em sua infância (Idem, p. 82). Na narrativa hagiográfica é dito que Frutuoso:

[...] construiu o monastério de Compludo segundo os preceitos divinos, sem reservar nada para si, ofertando ali até o último cêntimo de sua propriedade, o dotou abundantemente e o encheu com um exército de monges tanto das pessoas de sua própria casa como de conversos que ansiosamente precipitaram-se de toda a Hispania. ${ }^{30}$

\footnotetext{
30 "Nam construens cenobium Conplutensem iuxta diuina praecepta nichil sibi reseruans, omnem ase facultatis suae Ibidem conferens, eum locupletissime ditauit et tam ex familia sua quam ex conuersis ex diuersis Spaniae
} 
A dotação do monastério (mas não sua fundação) foi contestada pelo seu cunhado, que teve sucesso em buscar a justiça do rei alegando que deveria receber metade da herança dos pais de Frutuoso "sob o pretexto de comandar uma campanha". ${ }^{31}$ Após receber essas notícias, Frutuoso toma uma série de medidas: primeiro, remove os adornos da igreja, desnuda os altares e escreve para seu cunhado, "para confundi-lo, repreendê-lo e ameaçá-lo em nome do Senhor”. Em seguida, Frutuoso recorre às preces. O resultado, nas palavras do hagiógrafo, foi que o cunhado de Frutuoso, "esse invejoso dos homens santos e inimigo dos bons atos, foi imediatamente atingido pela vingança divina e rapidamente terminou sua vida” (DÍAZ Y DÍAZ, 1974, p. 84).

Devemos examinar dois aspectos dessa narrativa. Primeiro, o monastério foi ricamente dotado pelo patrimônio de Frutuoso - a herança disputada - e preenchido com monges. Mas esses monges eram não apenas os "conversos que ansiosamente precipitaram-se de toda a Espanha", mas também aqueles "de sua própria casa". Dada a origem aristocrática de Frutuoso e o alto posto de seu pai na hierarquia militar do Reino (um "ducis exercitus Spaniae"), é razoável assumir que o patrimônio da família deveria ser considerável e, provavelmente, era composto por diversas propriedades, camponeses dependentes, e expressava um grande poder local (DÍAZ MARTÍNEZ, 1998, p. 260-261; DÍAZ Y DÍAZ, 1974, p. 82). Essa hipótese é reforçada pela reação de cunhado, tanto em seu objetivo (receber metade da herança) quanto nos meios empregados (a intercessão do Rei e a caracterização do patrimônio como uma recompensa ou elemento para liderar uma campanha militar).

Devemos nos perguntar então quais eram os grupos sociais atraídos por Frutuoso e vinculados aos monastérios que ele construiu (não apenas Compludo). A questão está diretamente relacionada com o tipo de autoridade que Frutuoso teria sobre esses novos monges. ${ }^{32}$ Em outra passagem do texto, o hagiógrafo menciona que em meio a todos aqueles que foram atraídos pelo santo, alguns eram até mesmo nobres, e a maior parte desses nobres tornaram-se bispos. A individualização no discurso do hagiógrafo é explícita. ${ }^{33}$ Essa individualização deve ser oposta à generalização que ocorre quando o hagiógrafo escreve

partibus sedule concurrentibus eum agmine monachorum affluentissime compleuit" (DÍAZ Y DÍAZ, 1974, p. 84).

31 "pro exercenda publica expeditione conferretur" (DÍAZ Y DÍAZ, 1974, p. 84). Fear (1997, p. 125) aponta que o rei em questão seria provavelmente Chindasvinto.

${ }^{32}$ Frutuoso é o autor atribuído de uma regra monástica (CAMPOS RUIZ; ROCA MELIÁ, 1971, p. 129-162).

33 "multas idoneas ac nobiles personas". (DÍAZ Y DÍAZ, 1974, p. 90) 
sobre os seguidores de Frutuoso que não são nobres, a imensa maioria no discurso hagiográfico.

A hierarquização social - uma das expressões da generalização das relações de dependência pessoal - se manifestou em uma série de fenômenos, inclusive na fuga de dependentes no decorrer de todo o século VII. Isla Frez (2001) analisou a legislação régia destinada a combater essa movimentação de dependentes - um conjunto de vinte e uma leis na Lex Visigothorum - e, de acordo com o autor, essas devem ser caracterizadas como leis acerca de um grupo heterogêneo de dependentes que romperam os laços que os vinculavam a um dominus/patronus específico (ISLA FREZ, 2001, p. 113; ZEUMER, 1972, p. 351-365). Esse grupo estaria composto por uma variedade de pessoas mais ampla que apenas escravos, consistindo de "monges que abandonavam seus abades, clérigos que fugiam de seu bispo ou, claro, camponeses de diversas condições vinculados a um senhor" (ISLA FREZ, 2001, p. 123).

O desenvolvimento dessas leis indicou uma transformação das antigas relações para uma situação na qual "todos, incluindo os supostos delegados régios, se comportavam como senhores prontos a aumentar o número de seus dependentes" (ISLA FREZ, 2001, p. 120). Contudo, é importante notar que essa situação, longe da narrativa tradicional, não indica a decadência do Estado visigodo ou da sociedade, apenas sua transformação (ISLA FREZ, 2001, p. 120). Nesse contexto, a atuação de Frutuoso na VSF deve ser compreendida como evidência da expansão das relações de dependência pessoal. Quando o hagiógrafo enfatizou que o poder de atração de Frutuoso era tão imenso que pessoas "de toda a Espanha" precipitaram-se para os seus monastérios - sejam esses em Bierzo ou em Cádiz -, é evidente que tal movimento não poderia estar restrito apenas aos livres (CLAUDE, 1980).

A atuação de Frutuoso na VSF aparece como exemplo do mesmo processo estrutural que encontramos na ampla legislação sobre fugitivos. Isto é, um processo de disputa aristocrática por dependentes pessoais. Contudo, a unidade essencial entre (o controle da) terra e trabalho como os elementos fundamentais para a reprodução aristocrática não pode ser esquecida. Na disputa entre Frutuoso e seu cunhado, encontramos um conflito aristocrático provocado por um vácuo de poder (a morte do pai de Frutuoso). A principal questão aqui não é - ao contrário do que enfatiza o hagiógrafo - a conversão de Frutuoso e a fundação de Compludo. Parece razoável pensar que o apelo do cunhado de Frutuoso ocorreria mesmo na ausência desses eventos. Pois o que ele pedia ao Rei não era que esse cancelasse a fundação e dotação de Compludo, ou que a Frutuoso não fosse permitido entrar na vida monástica, mas que ele próprio deveria receber metade da herança como os meios para prestar serviços ao 
Rei. Em seu apelo, seu argumento central é que é justamente que aquele patrimônio havia sido concedido à família de Frutuoso justamente com esse objetivo. O hagiógrafo enquadra esse conflito em parâmetros religiosos, mas o que está realmente em questão é quem pode ser o sucessor de um grande poder aristocrático local. Aqui encontramos algumas sobreposições entre poderes aristocráticos laicos e eclesiástico, uma vez que o controle da terra e dependentes são as bases fundamentais de ambos.

A VSF é a hagiografia mais tardia de nosso corpus, tanto em seu período de composição (as últimas décadas do século VII) quanto no período representado em sua narrativa. De nossa análise anterior, o que emerge da $V S F$ é a imagem de uma sociedade estruturada não apenas por uma rígida hierarquia, mas também pela generalização das relações dependência pessoal. Encontramos o caráter geral desses processos tanto na disputa pela herança entre Frutuoso e seu cunhado (no noroeste da Península) quanto em outras passagens da hagiografia - por exemplo, nos conflitos entre Frutuoso e um grupo de aristocratas no extremo sul da Península (OROZ, 1978, p. 104-106). Em ambos os casos o que estava em questão não era a redução de livres ou libertos à dependência de um grande senhor, mas a afirmação do poder aristocrático através do controle de pessoas que já possuíam um estatuto dependente. Em um contexto de generalização das relações de dependência pessoal - onde as pessoas já vivem imersas nessas relações - o crescimento de um poder aristocrático só poderia ocorrer através do conflito com outros aristocratas e sobre o campesinato dependente. É precisamente esse o processo que encontramos em diversos casos retratados na VSF. O conflito entre Frutuoso e seu cunhado sobre a herança (dependentes e terra) do pai de Frutuoso é o processo de afirmação de dois "novos" poderes aristocráticos sobre os espólios de um em processo de desaparecimento.

\section{Conclusão}

As três hagiografias analisadas acima foram escolhidas para revelar dois elementos da sociedade visigoda: estrutura e dinâmica. Dessa forma, cada obra hagiográfica representa um "quadro" ou "imagem" da sociedade visigoda. Quando os colocamos lado a lado, dispomos de uma imagem geral geograficamente e cronologicamente diversificada: abrangendo quase a totalidade do século VII - as vitae analisadas foram redigidas entre 633 e 690 - e tendo como palco diversas regiões da Península - do norte (Berceo, na VSA) ao sudoeste (Mérida/VSPE); do Noroeste (Bierzo/VSF) ao sul (Cádiz/VSF).

Individualmente cada uma das hagiografias fornece evidências da estrutura social visigoda. A VSA e a VSPE são evidências para a estrutura social na primeira metade do século 
VII, uma fundada em um processo que vincula aristocratas (eclesiásticos) com um grupo heterogêneo cuja principal condição é seu estatuto não-aristocrático (pauperes e camponeses) através de tipo de troca de presentes específica (incompleta ou desigual). Os produtos desse intercâmbio são dependência e dominação. A VSF também é evidência da mesma estrutura social, mas na segunda metade do século VII. O que ela retrata é um panorama social no qual o processo acima descrito está quase completo: as relações de dependência pessoal entre aristocratas (não apenas eclesiásticos, mas também aristocráticos) e aquele grupo heterogêneo são o pressuposto dos dois casos na VSF que analisamos acima. Quando consideramos essas três hagiografias em conjunto como o processo que conecta os dois momentos históricos que representam (um pelas VSA/VSPE e o outro pela $V S F$ ), desvelamos a dinâmica social. Ela demonstra a transformação das relações de dependência pessoal de um processo histórico em desenvolvimento (VSA/VSPE) até o estabelecimento da lógica social do Reino Visigodo $(V S F)$. O que essa dinâmica revela são as transformações da sociedade visigoda, não como decadência progressiva, mas como a transformação da sociedade enquanto uma totalidade.

Tanto a VSA quanto a VSPE são evidências de um processo de dominação aristocrática sobre o campesinato, mas um tipo específico de dominação: um que está fundado na troca de presentes e onde é possível analisar o papel da aristocracia eclesiástica. Por outro lado, a VSF é o testemunho de um conflito intra-aristocrático (laico e eclesiástico) pelo controle desse campesinato dependente, mas um que parece ser fundamental, que é capaz tanto de opor quanto unir poderes locais e relacioná-los com a expressão da autoridade central - o Rei.

Na historiografia recente o dom aparece como "construções contestadas de transações sociais" e os sentidos dessas transações como se fosse " "negociadas' entre os atores sociais" (ALGAZI, 2003, p. 10). Mas seu escopo social é extremamente reduzido. Se o dom ainda almeja ser um "fato social total" não é possível que apenas diga respeito às relações aristocráticas. As análises acima tentaram demonstrar que longe de ser uma relação igualitária, balanceada e recíproca, o dom na Alta Idade Média Ibérica é um modo de dominação. Como um modo de dominação central, o dom é um vínculo entre aristocratas e camponeses em sua relação como dois grupos opostos. Esse vínculo funciona então como um mecanismo duplo: por um lado, o dom é capaz de balancear relações intra-aristocráticas como a relação entre Emiliano e Honório; por outro lado, o dom funciona como uma forma de dominação da aristocracia sobre o campesinato - como nas relações acima analisadas entre os santos e a multitude ou os pauperes. A troca de presentes como uma forma de dominação é tanto a expressão quanto o mecanismo de reprodução das relações de dependência pessoal. 


\section{REFERÊNCIAS}

\section{Fontes}

MAYA SÁNCHEZ, A. (Org.). Vitas sanctorum patrum emeretensium. Turnhout: Brepols, 1992. (Corpus christianorum. Series latina, 116).

OROZ, J. (Org.). Sancti Braulionis Caesaraugustani Episcopi. Vita Sancti Aemiliani. Perficit, v. IX, n. 119-120, p. 165-227, 1978. (Segunda Serie).

VÁZQUEZ DE PARGA, L. Sancti Braulionis Caesaraugustani episcopi Vita S. Emiliani. Madrid: Instituto Jerónimo Zurita, 1943.

ZEUMER, K. (Org.). Leges Visigothorum. Monumenta Germaniae Histórica. Leges nationum Germanicarum, 1. Hannoverae; Lipsiae: Impensis Bibliopolii Hahniani, 1972. (Monumenta Germaniae historica, I).

\section{Estudos}

ALGAZI, G.; GROEBNER, V.; JUSSEN, B. (Orgs.). Negotiating the gift: pre-modern figurations of exchange. Göttingen: Vandenhoeck \& Ruprecht, 2003.

ALGAZI, G. Introduction: Doing things with gifts. In: GROEBNER, Valentin; JUSSEN, B.; ALGAZI, G. (Orgs.). Negotiating the gift: pre-modern figurations of exchange. Göttingen: Vandenhoeck \& Ruprecht, 2003.

BARBERO, A.; VIGIL, M. La formación del feudalismo en la Península Ibérica. Barcelona: Editorial Crítica, 1978.

BARBERO, A.; VIGIL, M. Sobre los orígenes sociales de la Reconquista. Barcelona: Ariel, 1974. (Ariel quincenal, 91).

BERNARDO, J. Poder e dinheiro: do poder pessoal ao estado impessoal no regime senhorial. Séculos V - XV. Parte I: Sincronia, estructura economica e social do século VI ao século IX. Porto: Afrontamento, 1995.

BIJSTERVELD, A.-J. A. The medieval gift as agent of social bonding and political power: a comparative approach. In: COHEN, E.; DE JONG, M. B. (Orgs.). Medieval transformations: texts, power and gifts in context. Leiden [etc.]: Brill, 2001. (Cultures, beliefs and traditions, 11).

BROWN, P. Virtutes sanctorum ... strages gentium : "Deeds of Saints . . Slaughter of Nations". In: BROWN, P. The Rise of Western Christendom: Triumph and Diversity, A.D. 200-1000. Oxford: Wiley-Blackwell, 2013, p. 93-122.

CAMPOS RUIZ, J.; ROCA MELIÁ, I. (Orgs.). Reglas monásticas de la España visigoda: los tres libros de las "Sentencias". Madrid: La Editorial Católica, 1971. (Biblioteca de autores cristianos, 321). 
CASTELLANOS, S. La hagiografía visigoda: dominio social y proyección cultural. Logroño: Fundación San Millán de la Cogolla, 2004.

CASTELLANOS, S. Poder social, aristocracias y hombre santo en la Hispania visigoda: la Vita Aemiliani de Braulio de Zaragoza. Logroño: Universidad de La Rioja, 1998. (Biblioteca de investigación, 20).

CEREZO, T. M.; MONGE, J. E. El Léxico sobre relaciones de dependencia en un texto de Época Visigoda: Un ensayo Metodológico. Studia historica. Historia antigua, n. 6, p. 201210, 1988.

CLAUDE, D. Freedmen in the Visigothic Kingdom. In: JAMES, E. (Org.). Visigothic Spain: New Approaches. Oxford: Clarendon Press, 1980, p. 159-188.

CODOÑER MERINO, C. Sobre la "Vita Fructuosi". In: DE, C. L. A. et al (Orgs.). Athlon: satura grammatica in honorem Francisci R. Adrados. Madrid: Editorial Gredos, 1984, v. 2, p. 183-190. 2v. Disponível em: 〈http://dialnet.unirioja.es/servlet/libro?codigo=4694>. Acesso em: 24 jun. 2014.

COLLINS, R. Merida and Toledo: 550-585. In: JAMES, E. (Org.). Visigothic Spain: new approaches. Oxford: Clarendon Press, 1980, p. 189-219.

CURTA, F. Merovingian and Carolingian Gift Giving. Speculum, v. 81, n. 3, p. 671-699, 2006.

DAVIES, W.; FOURACRE, P. (Orgs.). The languages of gift in the early Middle Ages. Cambridge, UK ; New York: Cambridge University Press, 2010.

DÍAZ MARTÍNEZ, P. C. El Testamento de Vicente: Propietarios y Dependientes en la Hispania del s. VI. In: HIDALGO, M. J.; PÉREZ SÁNCHEZ, D.; GERVÁS, M. J. R. (Orgs.). "Romanización" y "Reconquista" en la Península Ibérica, nuevas perspectivas.

Salamanca: Ediciones Universidad de Salamanca, 1998, p. 257-270. (Acta salmanticensia. Estudios históricos y geográficos, 105).

DÍAZ Y DÍAZ, M. C. La vida de San Fructuoso de Braga: estudio y edición crítica. Braga: Imp. na Empresa do Diario do Minho, 1974.

ESPINOSA RUIZ, U. El enclave "Parpalines" de la "Vita Sancti Aemiliani": espacio rural y aristocracia en época visigoda. Iberia. Revista de la Antigüedad, v. 6, n. 0, p. 79-109, 2013.

FEAR, A. T. Lives of the Visigothic Fathers. [s.1.]: Liverpool University Press, 1997.

GARCÍA MORENO, L. A. Historia de España visigoda. Madrid: Cátedra, 1989.

GODELIER, M. O enigma do dom. Rio de Janeiro: Civilização Brasileira, 2001.

ISLA FREZ, A. Los fugitivos y el título sobre ellos del "Liber Iudicum". Arqueología y territorio medieval, n. 8, p. 113-124, 2001. 
MAUSS, M. Ensaio sobre a dádiva. In: Sociologia e antropologia. São Paulo: Cosac Naify, 2003, p. 183-314.

PACHÁ, Paulo Henrique. Gift and Conflict: Forms of Social Domination in the Iberian Early Middle Ages. Networks and Neighbours, v. 2, n. 2, p. 288-324, 2014.

PANZRAM, S. Mérida contra Toledo, Eulalia contra Leocadia: listados "falsificados" de obispos como medio de autorepresentación municipal. p. 123-130, 2010.

PASTOR, R.; RODRÍGUEZ LÓPEZ, A. Reciprocidades, intercambio y jerarquía en las comunidades medievales. Hispania: Revista española de historia, v. 60, n. 204, p. 63-101, 2000.

PÉREZ SÁNCHEZ, D. EI Ejército en la sociedad visigoda. Salamanca: Universidad de Salamanca, 1989.

VELÁZQUEZ SORIANO, I. La literatura hagiográfica: presupuestos básicos y aproximación a sus manifestaciones en la Hispania visigoda. Burgos: Fundación Instituto Castellano y Leonés de la Lengua, 2007. (Libros singulares, 17).

VELÁZQUEZ SORIANO, I. Vidas de los santos Padres de Mérida. Madrid: Editorial Trotta, 2008.

VIVES, J. (Org.). Concilios visigóticos e hispano-romanos. Barcelona: Consejo Superior de Investigaciones Científicas, Instituto Enrique Flórez, 1963.

WICKHAM, C. Conclusion. In: DAVIES, W.; FOURACRE, P. (Orgs.). The languages of gift in the early Middle Ages. Cambridge, UK ; New York: Cambridge University Press, 2010, p. 238-261.

WOOD, I. Entrusting Western Europe to the Church, 400-750. Transactions of the Royal Historical Society (Sixth Series), v. 23, p. 37-73, 2013.

WOOD, I. Social Relations in the Visigothic Kingdom from the Fifth to the Seventh Century: The Example of Merida. In: HEATHER, P. (Org.). The Visigoths: from the migration period to the seventh century. an ethnographic perspective. San Marino: The Boydell Press, 1999, p. 191-208. (Studies in historical archaeoethnology, 4).

WOOD, I. The exchange of gifts among the late antique aristocracy. In: GORBEA, M. A. (Org.). El disco de Teodosio. Madrid: Real Academia de la Historia, 2000, p. 301-314. (Publicaciones del Gabinete de Antigüedades de la Real Academia de la Historia, 5).

WOOD, I. The use and abuse of latin hagiography in the early medieval West. In:

CHRYSOS, E. K; WOOD, I. (Orgs.). East and West: modes of communication : proceedings of the first plenary conference at Merida. [s.1.]: Brill, 1999, p. 93-109. 